\title{
Assimetria entre paz, guerra e violência na concepção de crianças e adolescentes
}

\author{
Luciana Karine de Souza \\ Tania Mara Sperb ${ }^{1}$
}

\begin{abstract}
Resumo
Este trabalho investigou os conceitos de paz e guerra no Brasil e a presença de assimetria entre paz, guerra e violência. Foram entrevistadas 61 crianças e 63 adolescentes sobre causas da paz e da guerra; razões da preferência pela paz; estratégias pró-paz, antiguerra e antiviolência; e definição de paz ou guerra no Brasil. A hipótese de assimetria foi confirmada apenas nos participantes mais novos. A guerra no Brasil foi definida como violência, conflito de interesses e reivindicação; a paz brasileira, como ausência de violência e de guerra individual, emoções positivas, atitudes humanitárias e amizade. As crianças apresentaram dificuldades para definir paz e guerra no Brasil, predominando respostas não-classificáveis. Os participantes adolescentes preferiram estratégias prescritivas às proscritivas. Espera-se que os dados do presente estudo contribuam para o desenvolvimento de programas de educação para a paz que atentem para a influência dos conceitos de guerra e violência sobre o de paz.

Palavras-chave: Psicologia para a paz; Guerra; Violência; Assimetria.
\end{abstract}

\section{Asymmetry among peace, war, and violence according to children and adolescents}

\begin{abstract}
This study investigated the concepts of peace and war in Brazil, and the presence of asymmetry among peace, war, and violence. Sixty-one children and sixty-three adolescents were interviewed about the definition of peace or war in Brazil; causes of peace and war; reasons for choosing peace over war; and strategies pro-peace, against war, and against violence. The asymmetry hypothesis was confirmed only in children's answers. War in Brazil was defined as violence, conflict of interests, and demand; Brazilian peace, as absence of violence, absence of individual war, positive emotions, humanitarian attitudes, and friendship. Children presented difficulties on the definitions of peace and war in Brazil, presenting a large number of unclassifiable answers. Older participants preferred prescriptive strategies. This study may contribute to the development of peace education programs that takes into account the influence of war and violence ideas on the conceptualization of peace.
\end{abstract}

Keywords: Peace psychology; War; Violence; Asymmetry.

\section{Introdução}

Segundo Aron (1986), "a guerra é de todas as épocas e de todas as civilizações. Os homens sempre se mataram, empregando os instrumentos fornecidos pelo costume e a técnica disponível" (p. 219). Já paz, para o autor, significa a suspensão das modalidades violentas da rivalidade entre as nações, pois "se fundamenta na potência, isto é, na relação entre os diferentes graus da capacidade que têm as unidades políticas de agir umas sobre as outras" (p. 220). Essa concepção assemelha-se à de Pax Romana, que indicava o intervalo vitorioso entre batalhas (Guimarães, 2003). Observa-se, dessa forma, que a noção de guerra se faz presente na definição de paz, caracterizando-a como ausência de guerra (ou de violência).

Pesquisas com crianças e adolescentes de diferentes culturas têm indicado que os conceitos de paz e de guerra desenvolvem trajetórias distintas (Hägglund, 1999, na Suécia; Hakvoort, 1996, na Holanda; McLernon \& Cairns, 1999, na Irlanda do Norte; Punamäki, 1999, na Palestina; Raviv, Bar-Tal, Koren-Silvershatz \& Raviv, 1999, em Israel). O conceito de guerra emerge previamente ao de paz. Este último, por sua vez, surge primeiramente como paz negativa, isto é, paz definida como ausência de guerra ou de violência. A noção de paz negativa é seguida pela de paz positiva, qual seja, a paz pela cooperação e pela coexistência harmônica. $\mathrm{Na}$ visão de Oppenheimer (1996), as crianças conseguem definir paz positiva somente após definirem guerra e paz negativa, porque "as concepções de paz positiva parecem depender do desenvolvimento de habilidades cognitivas e sociocognitivas adicionais" (p. 203).

A paz definida como ausência de guerra - tanto por estudiosos (Aron, 1986) como por crianças de culturas distintas - revela, segundo Oppenheimer (1996),

\footnotetext{
${ }^{1}$ Endereço para correspondência:

Rua Felicíssimo de Azevedo, 1.443 - apto 402 - Bairro Auxiliadora - 90540-110 - Porto Alegre-RS

Fone: (51) 3316-5246 - Fax: (51) 3316-5473

E-mails: sperbt@terra.com.br - luciana.karine@ufrgs.br
} 
uma assimetria entre os dois conceitos. Isso ocorre porque a definição de paz que prevalece não é a de paz positiva, mas sim a de paz negativa, que se fundamenta no contraste com o conceito de guerra. Para o autor, essa assimetria entre paz e guerra justifica-se: "normas, valores e atitudes que promovem a guerra são enfatizados em vez daqueles que promovem a paz" (p. 202). Nesta mesma direção, Lourenço (1999) observou que, "embora muito falemos sobre paz, é a guerra que é aparente, difundida e onipresente" (p. 91). Em muitas culturas, os indivíduos conceituam paz como negação de guerra; entretanto, guerra não é definida como negação de paz. Em um estudo que conduziu com crianças portuguesas entre cinco e nove anos de idade, Lourenço (1999) pôde observar a prevalência da guerra ou de idéias negativas. Apesar de não ter analisado, nessa pesquisa, a simetria entre paz e guerra, o autor notou que,

questionadas a escolher entre sancionar um ato positivo $e$ um ato negativo relacionados a dominios morais, prósociais e acadêmicos, as crianças afirmam que as pessoas não têm que ser elogiadas por fazer algo que devem fazer, mas elas sempre devem ser culpadas ou até mesmo punidas por mau comportamento. (p. 97)

Assim, tanto para Oppenheimer como para Lourenço, a humanidade vive sob a cultura da guerra, o que justifica a assimetria observada entre os conceitos de paz e guerra.

No Brasil, Biaggio e Souza (2001) investigaram os conceitos de paz, de guerra e de violência em estudantes de oitava série e universitários. $\mathrm{Na}$ discussão da pesquisa, as autoras referiram que alguns dos resultados encontrados favorecem a hipótese de Lourenço (1999) para a assimetria entre paz e guerra. Embora Biaggio e Souza não tenham feito predições sobre assimetria, sugeriram que fosse considerada em estudos posteriores. Já quanto aos conceitos de paz, de guerra e de violência, as pesquisadoras referidas relataram os conteúdos que compuseram esses conceitos. Observaram que tanto guerra como paz foram definidas com conteúdos que se aproximaram às respostas obtidas nos estudos europeus: guerra foi definida principalmente quanto a conflitos bélicos entre países e a conseqüências dos embates; ao passo que paz foi mais referida pela ausência desses conteúdos (por exemplo, paz é ausência de guerras entre países).

O presente trabalho teve dois objetivos. O primeiro consistiu em investigar os conceitos de paz e de guerra no contexto brasileiro, isto é, o conceito de paz no Brasil e o conceito de guerra no Brasil. A expectativa foi de que ambos se mostrassem mais associados à experiência brasileira com o problema da violência do que de conflitos internacionais. A segunda metade deste estudo investigou a hipótese de assimetria nos conceitos de paz, de guerra e de violência, em crianças e adolescentes. Esperou-se observar assimetria entre paz e guerra e entre paz e violência (Biaggio \& Souza, 2001; Lourenço, 1999; Oppenheimer, 1996).

\section{Método}

\section{Participantes}

Participaram deste estudo 61 crianças (30 meninos e 31 meninas) com média de idade de 7,6 anos $(D P=0,82)$ e 63 adolescentes (29 meninos e 34 meninas) com média de idade de 12,7 anos $(D P=0,72)$. Os participantes mais novos cursavam o $2^{\circ}$ ano do ensino fundamental; os mais velhos, o $7^{\circ}$ ano. Todos estavam matriculados em uma escola pública de nível socioeconômico médio da área central de Porto Alegre, capital do Rio Grande do Sul. A região central de Porto Alegre apresenta taxas elevadas de crimes contra pessoas e posses, de criminalidade urbana violenta (isto é, homicídios, roubos, estupros, seqüestros) e de mortes por acidentes de trânsito. Em contrapartida, a região figura em terceiro lugar no ranking de qualidade de vida da cidade de Porto Alegre, apresentando o maior índice de escolaridade e as maiores ofertas educacionais e culturais (Tavares dos Santos \& Russo, 2003).

\section{Instrumentos}

Duas entrevistas foram utilizadas: uma sobre paz e outra sobre guerra. A entrevista sobre paz continha as seguintes perguntas: 1) Por que algumas pessoas querem a paz? 2) Dois países estão em paz entre si. Se tu fosses dono(a) do mundo, o que tu farias para que eles ficassem nesta paz? 3) Tu achas que a paz é melhor do que a guerra? Por quê? 4) Tu achas que tem paz no Brasil? Como é essa paz? 5) Como se pode parar a violência? A entrevista sobre guerra era composta das seguintes questões: 1) Por que algumas pessoas fazem a guerra? 2) Dois países estão em guerra entre si. Se tu fosses dono(a) do mundo, o que tu farias para eles pararem esta guerra? 3) Tu achas que a paz é melhor do que a guerra? Por quê? 4) Tu achas que tem guerra no Brasil? Como é esta guerra? 5) Como se pode parar a violência?

As questões de 1 a 3, de ambas as entrevistas, foram baseadas no trabalho de Lourenço (1999) e dizem respeito, respectivamente, às causas da paz ou da guerra, estratégias pró-paz ou antiguerra, e razões para se preferir a paz (efetuada de modo idêntico nas duas entrevistas). Já as questões 4 e 5 (definição de paz ou guerra no Brasil, e estratégias antiviolência, respectivamente) foram elaboradas especialmente para o presente trabalho. 


\section{Delineamento e procedimento}

Realizou-se um estudo exploratório, com quatro grupos, organizados por tipo de entrevista, faixa etária e sexo. Dois grupos responderam a perguntas sobre paz e violência: um grupo de 30 crianças (15 meninos e 15 meninas) e outro de 34 adolescentes (15 rapazes e 19 moças). Outros dois grupos foram entrevistados sobre guerra e violência: 31 crianças (15 meninos e 16 meninas) e 29 adolescentes (15 moças e 14 rapazes).

As entrevistas ocorreram na escola, em uma sala cedida especialmente para este fim. Os alunos foram entrevistados individualmente durante um período de, em média, 15 minutos. As entrevistas foram gravadas em audioteipe e posteriormente transcritas. Foram obtidos consentimentos informados da escola, dos pais ou responsáveis pelos alunos, e de todos os participantes adolescentes, nesta ordem.

\section{Análise dos dados}

Para as questões número 1, 2, 3 e 5 de ambas as entrevistas, respostas afins foram agrupadas em categorias mutuamente exclusivas, pré-selecionadas, baseadas no estudo de Lourenço (1999), descritas a seguir. As respostas sobre as causas da paz foram analisadas conforme as seguintes categorias: razões de paz positiva (paz promove eventos positivos variados, como amizade, compreensão, respeito) ou de paz negativa (paz evita eventos indesejáveis variados, como não discutir e não brigar). As causas da guerra foram categorizadas de acordo com razões orientadas para a guerra (para obter poder, vantagem, por retaliação ou para prejudicar, e para se defender) ou para a paz (fazer guerra para viver em paz, ou melhorar o bem-estar de outrem). As categorias utilizadas na classificação das respostas dos três tipos de estratégias (relativas à paz, guerra ou violência) foram as mesmas: estratégias prescritivas, "se as crianças apelaram para ações ou atividades positivas, [...] intervenção prósocial, negociação, diálogo e reflexão; compromisso e remoção das causas da guerra"; e estratégias proscritivas, "se as crianças se referiram a estratégias que envolveram mais omissão e passividade do que ação ou atividade, [...] intervenção agressiva e cessação da guerra de forma unilateral; estratégias negativas ou de ausência de guerra" (Lourenço, 1999, p. 100-102). As razões da preferência pela paz foram categorizadas em dois tipos: razões orientadas para a paz negativa (a paz evita as conseqüências da guerra) e para a paz positiva (a paz traz resultados positivos). $\mathrm{Na}$ categorização das respostas às questões sobre causas, estratégias e razões de preferência pela paz foram utilizadas categorias para respostas mistas, que continham a combinação de respostas das categorias de análise; e resposta não-classificável (o participante não respondeu à questão ou desviou-se do tema). Assim, a grade de análise para cada uma das questões 1, 2, 3 e 5 é composta por quatro categorias, mutuamente exclusivas (ou seja, apenas uma delas poderia ser identificada na resposta).

As categorias para a análise das respostas às questões de número 4 - sobre as definições de paz ou de guerra no Brasil - foram retiradas do estudo de Hakvoort (1996). São elas: ausência de guerra global, ausência de guerra individual, ausência de mortes, emoções positivas e atitudes humanitárias, para as questões sobre paz; e mortes, emoções negativas, conflito individual e conflito de interesses, para as questões sobre guerra. Categorias adicionais emergiram de análise de conteúdo, segundo os critérios de Bardin (1977), e são descritas nos resultados. Para cada uma das categorias sobre paz no Brasil ou sobre guerra no Brasil, calculou-se inicialmente a porcentagem total de respostas, sem distinção etária ou de sexo. Assim, as categorias que apresentaram porcentagem menor que 10 nessa análise prévia foram descartadas das análises subseqüentes. Cabe mencionar que as categorias para as questões 4 das duas entrevistas não eram de uso exclusivo, ou seja, em cada resposta era possível identificar mais de uma categoria.

Foram calculadas freqüências e porcentagens de respostas em cada categoria, de todas as questões, nas duas entrevistas, para cada um dos quatro grupos de participantes: meninos, meninas, rapazes e moças. Posteriormente, efetuou-se o cálculo do qui-quadrado, com base nas freqüências, na busca de associações entre categorias e grupos, ao nível de significância de 0,05. Quando necessário, análises complementares foram realizadas entre categorias e dois grupos etários (crianças e adolescentes), sem distinção de sexo. Dois juízes analisaram 24 entrevistas (12 de paz e 12 de guerra), divididas igualmente por faixa etária e sexo. Comparadas as análises de ambos os juízes, avaliou-se a confiabilidade interjuízes pelo cálculo do coeficiente Kappa, que variou de 0,82 a 1,00 nas respostas analisadas.

\section{Resultados}

Os resultados são apresentados por tema: paz, guerra e violência. Primeiramente são descritos os dados obtidos com a entrevista sobre paz, quais sejam, as causas da paz, estratégias pró-paz, razões da preferência pela paz e definição de paz no Brasil. A Tabela 1 apresenta as freqüências e porcentagens de respostas nas categorias sobre paz, por grupo, citadas, pelo menos, por três dos quatro grupos estudados. 
Tabela 1 - Freqüência e porcentagem de respostas nas categorias sobre paz, por grupo

\begin{tabular}{|c|c|c|c|c|c|}
\hline \multirow[b]{2}{*}{ Questão } & \multirow[b]{2}{*}{ Categoria } & \multicolumn{2}{|c|}{ Crianças } & \multicolumn{2}{|c|}{ Adolescentes } \\
\hline & & $\begin{array}{c}\text { Meninos } n=15 \\
\mathrm{fa}^{\mathrm{a}}(\%)\end{array}$ & $\begin{array}{c}\text { Meninas } n=15 \\
\mathrm{f}(\%)\end{array}$ & $\begin{array}{c}\text { Rapazes } \mathrm{n}=15 \\
\mathrm{f}(\%)\end{array}$ & $\begin{array}{c}\text { Moças } \\
\mathrm{n}=19 \\
\mathrm{f}(\%)\end{array}$ \\
\hline \multirow{3}{*}{ Causas da paz } & paz positiva & $2(13)$ & $3(20)$ & $1(7)$ & $1(5)$ \\
\hline & paz negativa & $7(47)$ & $7(47)$ & $2(13)$ & $6(32)$ \\
\hline & mistas & $4(27)$ & $4(27)$ & $11(73)$ & $9(47)$ \\
\hline \multirow{3}{*}{$\begin{array}{l}\text { Estratégias pela } \\
\text { paz }\end{array}$} & prescritivas & $2(13)$ & $3(20)$ & $11(73)$ & $12(63)$ \\
\hline & proscritivas & $8(53)$ & $9(60)$ & $4(27)$ & $4(21)$ \\
\hline & mistas & $5(33)$ & $2(13)$ & $-\mathrm{b}$ & $3(16)$ \\
\hline \multirow{2}{*}{$\begin{array}{l}\text { Preferência pela } \\
\text { paz }\end{array}$} & paz negativa & $9(60)$ & $8(53)$ & $6(40)$ & $4(21)$ \\
\hline & mistas & $6(40)$ & $5(33)$ & $9(60)$ & $15(79)$ \\
\hline \multirow{5}{*}{ Paz no Brasil } & & $\mathrm{n}=11$ & $\mathrm{n}=14$ & $\mathrm{n}=7$ & $\mathrm{n}=9$ \\
\hline & sem violência & $3(27)$ & $4(29)$ & $1(14)$ & $1(11)$ \\
\hline & emoções positivas & $1(9)$ & $2(14)$ & $2(29)$ & $3(33)$ \\
\hline & atitudes humanitárias & $2(18)$ & $1(7)$ & $2(29)$ & $2(22)$ \\
\hline & amizade & - & $3(21)$ & $2(29)$ & $2(22)$ \\
\hline
\end{tabular}

$\mathrm{f}^{\mathrm{a}}=$ freqüência $\quad{ }^{\mathrm{b}} \mathrm{O}$ sinal negativo indica a ausência de respostas na categoria.

Como se pode observar na Tabela 1 , nas causas da paz as crianças preferiram as razões de paz negativa; os adolescentes, as razões mistas. As razões de paz positiva foram preteridas por todos os grupos na comparação com os demais tipos. Foram encontradas $11 \%$ de respostas nãoclassificáveis nesta questão. $\mathrm{O}$ teste de qui-quadrado não revelou associação significativa entre as categorias e os quatro grupos, apenas entre categorias e os dois grupos etários (crianças e adolescentes), com a escolha dos participantes mais velhos pelas razões mistas.

No processo de categorização das estratégias própaz, encontraram-se conteúdos não diretamente referidos na categorização de Lourenço (1999). Estes conteúdos (ajudar, acordo, diálogo, tratado, amizade, dividir, dar comida, conscientizar, igualdade, direitos iguais, união e liberdade) foram, no presente estudo, considerados como estratégias prescritivas. Da mesma forma, categorizou-se como estratégias proscritivas as seguintes respostas: dizer para parar, mandar parar, mandar ficar em paz, punir, fazer uma lei, chamar a polícia, não fazer nada, dizer para cada um cuidar de si, fazer o que se pede, e desarmar. Enquanto as crianças apresentaram mais estratégias proscritivas, os adolescentes preferiram as prescritivas. O grupo dos rapazes foi o único a não mencionar estratégias mistas, categoria preferida pelos meninos. Apenas um participante (uma menina) apresentou resposta não-classificável. Encontrou-se associação significativa entre categorias e grupos: rapazes $(73 \%)$ e moças $(63 \%)$ destacaram-se nas estratégias prescritivas; os meninos, nas mistas $(33 \%)\left(\chi^{2}(9\right.$, $\mathrm{N}=64)=23,05, p=0,006)$.

Nas razões da preferência pela paz (conforme os entrevistados sobre paz), enquanto as crianças preferiram as razões orientadas para a paz negativa, os adolescentes referiram mais razões mistas. Razões orientadas para a paz positiva e respostas não-classificáveis foram ambas mencionadas por um participante apenas $(7 \%)$ - estes resultados não constam na Tabela 1. Encontrou-se associação significativa entre as razões da preferência pela paz e grupos, com as moças destacando razões mistas $(79 \%)\left(\chi^{2}(9, \mathrm{~N}=64)=14,10, p=0,049\right)$.

Com relação à paz no Brasil, 13 estudantes (20,3\%) responderam que sim, existe paz no país; 28 alunos $(43,8 \%)$ responderam mais ou menos, às vezes ou em parte (respostas indecisas); e 23 participantes (35,9\%) disseram que não há paz no Brasil. As respostas afirmativas e indecisas (total de 41 participantes) conduziram a nove categorias de respostas, das quais cinco obtiveram porcentagem total superior a 10 , sem distinção etária ou de sexo: ausência de violência (22\%); emoções positivas (como amor, carinho, felicidade) (19,5\%); atitudes humanitárias (respeitar, compartilhar) (17\%); ausência de guerra individual (brigar, dar soco, pontapé) (17\%) e amizade $(12 \%)$. As respostas não-classificáveis obtiveram $17 \%$, originadas de entrevistas com participantes mais novos. Este resultado responde à expectativa sobre diferenças etárias na definição de paz. $\mathrm{Na}$ análise dos grupos, apenas as meninas e as moças citaram ausência de guerra individual (29\% e 33\%, respectivamente), e o grupo dos meninos foi o único a não referir amizade como indicativo de paz no Brasil. Os cruzamentos entre grupos e cada categoria não apresentaram associação significativa.

Passa-se a seguir à apresentação dos resultados encontrados sobre o tema da guerra. A Tabela 2 exibe as freqüências e porcentagens de respostas nas categorias sobre guerra, por grupo, citadas, pelo menos, por três dos quatro grupos estudados. 
Tabela 2 - Freqüência e porcentagem de respostas nas categorias sobre guerra, por grupo

\begin{tabular}{llcccc}
\hline & & \multicolumn{2}{c}{ Crianças } & \multicolumn{2}{c}{ Adolescentes } \\
Questão & Categoria & Meninos & Meninas & Rapazes & Moças \\
& & $\mathrm{n}=15$ & $\mathrm{n}=16$ & $\mathrm{n}=14$ & $\mathrm{n}=15$ \\
& & $\mathrm{fa}(\%)$ & $\mathrm{f}(\%)$ & $\mathrm{f}(\%)$ & $\mathrm{f}(\%)$ \\
\hline Causas da guerra & orientadas p/ guerra & $11(73)$ & $12(75)$ & $12(86)$ & $13(87)$ \\
Estratégias antiguerra & prescritivas & $1(7)$ & $1(6)$ & $12(86)$ & $13(87)$ \\
& proscritivas & $11(73)$ & $11(69)$ & $2(14)$ & $2(13)$ \\
\hline \multirow{3}{*}{ Preferência pela paz } & paz positiva & $2(13)$ & $2(12,5)$ & $-\mathrm{b}$ & $1(7)$ \\
& paz negativa & $10(67)$ & $7(44)$ & $4(29)$ & $5(33)$ \\
& mistas & $3(20)$ & $7(44)$ & $10(71)$ & $9(60)$ \\
\hline \multirow{3}{*}{ Guerra no Brasil } & & $\mathrm{n}=7$ & $\mathrm{n}=7$ & $\mathrm{n}=12$ & $\mathrm{n}=14$ \\
& violência & $4(57)$ & - & $5(42)$ & $5(36)$ \\
\hline
\end{tabular}

$\mathrm{f}^{\mathrm{a}}=$ freqüência

-b $\mathrm{O}$ sinal negativo indica a ausência de respostas na categoria

Nas causas da guerra, a maioria dos 60 participantes entrevistados sobre guerra optou por razões orientadas para a guerra. Quanto às demais categorias, enquanto os meninos e as moças foram os únicos a indicarem razões orientadas para a paz $(13 \%$ e $7 \%$, respectivamente), as meninas e os rapazes foram responsáveis pelas porcentagens das respostas mistas $(6 \%$ e 14\%, nesta ordem). A categoria não-classificável totalizou 10\% das respostas (oriundas de cinco crianças e um adolescente). Nesta questão, não foram encontradas diferenças estatisticamente significativas entre grupos e categorias.

Nas estratégias antiguerra, os adolescentes preferiram as estratégias prescritivas; as crianças, as proscritivas. Além disso, apenas os participantes mais novos mencionaram estratégias mistas, sendo $20 \%$ por meninos e $25 \%$ por meninas. Encontrou-se associação significativa entre estratégias prescritivas e adolescentes, e entre estratégias proscritivas e crianças, sem distinção de $\operatorname{sexo}\left(\chi^{2}(2, \mathrm{~N}=60)=39,03, p<0,000\right)$.

$\mathrm{Na}$ questão a respeito das razões da preferência pela paz, os entrevistados sobre guerra preferiram razões mistas (adolescentes) e de paz negativa (crianças) às de paz positiva. As razões orientadas para a paz negativa foram preferidas pelas crianças na comparação com os estudantes mais velhos. O teste de qui-quadrado não acusou associação significativa entre os quatro grupos e razões da preferência pela paz. Nos cruzamentos entre os grupos etários (crianças e adolescentes) e categorias encontrou-se associação significativa entre adolescentes e razões mistas $\left(\chi^{2}(2, N=60)=6,99, p=0,03\right)$.

Com relação à presença de guerra no Brasil, 29 estudantes $(48,3 \%)$ responderam que existe guerra no país; 11 alunos $(18,4 \%)$ responderam mais ou menos, às vezes ou em parte (respostas indecisas); e 20 participantes $(33,3 \%)$ disseram que não há guerra no Brasil. Os estudantes que responderam positivamente bem como os indecisos somaram 40 participantes. Da análise realizada nessas entrevistas obtiveram-se sete categorias de respostas, das quais três apresentaram porcentagem superior a 10 (sem distinção etária ou de sexo): violência (violência, assaltos, tiroteio, gangues, traficantes, conflitos entre policiais e criminosos, violência policial, bandidos, facadas, briga) (37,5\%); conflito de interesses (entre políticos, entre classes sociais, disputas, divergências, racismo) (22,5\%); e reivindicação (guerra no Brasil é protestar por melhores salários, mais empregos, contra a fome; lutar por direitos) (20\%). As respostas nãoclassificáveis, oriundas exclusivamente de entrevistas com crianças, totalizaram 17,5\%. $\mathrm{Na}$ análise por grupos, os meninos apresentaram respostas unicamente na categoria violência $(57 \%)$. As meninas mencionaram apenas conflito de interesses para definir guerra no Brasil (29\%). A categoria reivindicação foi inteiramente composta por respostas de adolescentes, sendo 33\% de respostas de rapazes e $29 \%$ de moças. Os cruzamentos entre categorias e grupos não revelaram associação significativa.

Como a questão sobre estratégias antiviolência esteve presente nas duas entrevistas, todos os 124 participantes do estudo responderam-na, totalizando 30 meninos, 31 meninas, 29 rapazes e 34 moças. Em dez participantes $(8 \%)$ não foi possível classificar a resposta conforme a grade disponível de categorias. As estratégias prescritivas, preferidas pelos adolescentes, tiveram maior porcentagem nas respostas das moças (65\%), seguidas dos rapazes $(55 \%)$, das meninas $(26 \%)$ e dos meninos $(13 \%)$. $\mathrm{O}$ grupo dos meninos foi o que mais apresentou estratégias proscritivas $(60 \%)$, seguidos pelas meninas $(45 \%)$, rapazes $(17 \%)$ e moças $(12 \%)$. As estratégias mistas foram mais citadas pelas crianças, especialmente pelos meninos (27\%), seguidos das meninas (23\%), rapazes $(17 \%)$ e moças $(9 \%)$. O teste de qui-quadrado 
apontou associação significativa entre estratégias antiviolência e grupos, com destaque para meninos e estratégias proscritivas, e moças e estratégias prescritivas $\left(\chi^{2}(9, \mathrm{~N}=124)=36,12, p<0,000\right)$.

\section{Discussão}

Os resultados são discutidos em três sessões distintas, organizadas por tema: paz, guerra e violência. Em cada sessão são analisadas as expectativas quanto à assimetria e às diferenças etárias e de sexo. Os resultados sobre paz e sobre guerra são comparados em virtude da expectativa de assimetria entre estes conceitos. Encerra-se o trabalho com considerações metodológicas sobre a pesquisa apresentada, sobre as experiências com paz, guerra e violência no Brasil e sobre futuros trabalhos.

\section{As expectativas do estudo nas entrevistas sobre paz.}

Observou-se assimetria parcial nas respostas a todas as questões da entrevista sobre paz, com exceção das razões pela preferência pela paz, nas quais todos os participantes preteriram razões positivas. Nas causas da paz os resultados foram favoráveis à assimetria somente na amostra de crianças, que preferiram razões de paz negativa. Ainda assim, todos os participantes preteriram razões de paz positiva, o que indiretamente favorece a hipótese de Lourenço (1999). Nas estratégias pró-paz, a expectativa com relação à assimetria também se confirmou apenas nas crianças, que indicaram estratégias proscritivas para manter a paz. Na definição de paz no Brasil, obtiveram-se quatro categorias com temas negativos (ausência de violência, de guerra individual, de guerra global e de mortes) contra três categorias com temas positivos (emoções positivas, atitudes humanitárias e amizade). A assimetria mostrou-se presente, na definição de paz, nas porcentagens de respostas da amostra adolescente, que foram superiores nas categorias de temas positivos, na comparação com as crianças.

As diferenças etárias vão ao encontro do que menciona a revisão de literatura dos estudos sobre os conceitos de paz e de guerra, referida na introdução. $\mathrm{Na}$ comparação com os adolescentes, as crianças apresentaram mais respostas negativas do que positivas, em quase todas as questões. Também se observou que, na definição da paz no Brasil, os adolescentes destacaram atitudes humanitárias. Segundo Hakvoort e Oppenheimer (1998) e Oppenheimer, Bar-Tal e Raviv (1999), respeito e compreensão - presentes em atitudes humanitárias (Hakvoort, 1996) - são conteúdos abstratos que passam a integrar o conceito de paz apenas na adolescência. As crianças apresentaram mais respostas não-classificáveis, na comparação com os adolescentes, o que indica, segundo a literatura, dificuldades para verbalizar sobre paz, o que também foi observado nas estratégias pró-paz, razões da preferência pela paz, e na definição de paz no Brasil.

Encontrou-se apenas uma diferença de sexo significativa nas questões sobre paz: nas razões de preferência pela paz, as moças destacaram-se nas respostas mistas. Ainda assim, mesmo não significativos (segundo os testes de qui-quadrado realizados), há outros resultados sugerindo diferenças de sexo. Por exemplo, as meninas foram as únicas a compor a categoria de motivos positivos para manter a paz. Nas causas da paz, os rapazes apresentaram a maior porcentagem de respostas mistas. Nas estratégias, os rapazes salientaram mais as táticas prescritivas do que as participantes do sexo oposto. $\mathrm{Na}$ definição paz no Brasil, apenas as moças citaram ausência de guerra individual, constituíram maioria ao mencionar amizade, e relataram mais emoções positivas do que os participantes do sexo oposto. Como se verá mais adiante, apenas as distinções de sexo reveladas na definição de paz vão ao encontro do que referem os autores sobre a influência do sexo na concepção de paz e de guerra (Hakvoort \& Oppenheimer, 1998).

\section{As expectativas do estudo nas entrevistas sobre guerra}

Nas causas da guerra, a expectativa de assimetria confirmou-se, visto que a maioria dos participantes, de ambos os grupos etários examinados, escolheu razões orientadas para a guerra. Nas estratégias antiguerra, a hipótese de assimetria confirmou-se apenas parcialmente, nas estratégias proscritivas apontadas pelas crianças. Os estudantes mais velhos, ao contrário, preferiram estratégias prescritivas, contradizendo a assimetria esperada também para esse grupo etário. Nos motivos para a preferência da paz à guerra, a expectativa de assimetria também encontrou respaldo somente nos alunos mais novos (razões orientadas para a paz negativa). Ainda assim, a categoria razões orientadas para a paz positiva foi a menos escolhida pelas duas faixas etárias, o que poderia, em parte, responder à hipótese de assimetria.

$\mathrm{Na}$ definição da guerra no Brasil, é interessante notar como um conceito que, a princípio, estimularia apenas conteúdos negativos, foi indicado pelos adolescentes para manifestar atitudes afirmativas, como a luta por direitos, por respeito, por melhores condições de vida, representada por passeatas e greves - categoria reivindicação. Ainda assim, a guerra no Brasil não foi definida como ausência de paz pelos participantes do estudo, confirmando a assimetria no conceito de guerra para o contexto brasileiro.

Diferenças etárias foram observadas nas estratégias antiguerra e na definição de guerra no Brasil, em consonância com a revisão da literatura. Conforme os estudos de Hakvoort (1996), Hakvoort e Oppenheimer 
(1998), e Oppenheimer, Bar-Tal e Raviv (1999), tanto na idéia de paz como na de guerra os adolescentes apresentam respostas de conteúdo mais abstrato, diferençando-se das crianças. $\mathrm{Na}$ guerra no Brasil, os participantes mais velhos destacaram-se com a categoria reivindicação ao se referirem à luta por direitos como uma guerra por direitos. Este resultado denota não apenas maturidade intelectual, mas a conscientização dos conflitos político-sociais de sua própria sociedade.

De acordo com a literatura, as crianças deste estudo deveriam estar aptas a definir guerra. Não foi o que se observou na definição da guerra no Brasil, pelas respostas não-classificáveis mencionadas exclusivamente por meninos e meninas. Possivelmente a delimitação da guerra no Brasil (ou seja, a guerra associada ao contexto brasileiro) pode ter restringido as respostas das crianças pelo fato de não haver guerras no Brasil, no sentido tradicional de guerra, visto que aqui não existem conflitos bélicos como os vistos na mídia (isto é, guerras entre países, com tanques, bombas e soldados). Assim, a ausência de exemplos concretos de guerra, no país, pode ter dificultado a compreensão das crianças do presente estudo sobre uma guerra no Brasil. Ao final, não foram encontradas diferenças significativas de sexo nas entrevistas sobre guerra.

\section{As expectativas do estudo nas estratégias antiviolência}

Nas estratégias antiviolência, apenas os participantes mais novos corresponderam à assimetria esperada, escolhendo estratégias proscritivas. Os mais velhos optaram por estratégias prescritivas, contrariando a expectativa. Estes dados se assemelham àqueles encontrados nas estratégias pró-paz e nas estratégias antiguerra. Também foram semelhantes as diferenças etárias e de sexo encontradas (os meninos salientando estratégias proscritivas; as meninas, prescritivas), confirmando-se as expectativas quanto a estas distinções.

Da mesma forma que nas outras questões, repete-se aqui a atitude positiva dos adolescentes que contrariam a assimetria observada por Lourenço (1999) em suas investigações com crianças portuguesas. Entretanto, é interessante notar que, naquelas pesquisas, os participantes eram crianças de no máximo 12 anos de idade. Nesse caso, os resultados obtidos com a amostra de crianças no presente estudo confirmam a assimetria esperada pelo referido autor.

Ainda que os temas abordados sobre as categorias qualificadas de prescritivas e de proscritivas não estejam no foco das análises, é interessante mencioná-los para fins de contraste entre as amostras de adolescentes e de crianças. No conteúdo das estratégias antiviolência, das 12 crianças que mencionaram estratégias prescritivas, 7 mencionaram amizade. Como salienta Hägglund (1999), as crianças em idade escolar estão bastante envolvidas na formação de amizades e, conseqüentemente, dedicadas a selecionarem quais colegas são seus amigos e quais não são. Esta escolha fundamenta-se principalmente nos valores advindos da cultura na qual a criança está inserida. Dessa forma, compreende-se por que, nas estratégias prescritivas das crianças, encontraram-se respostas como "fazer amigos", "fazer amizade com os outros" e "todo mundo ser amigo". Já no conteúdo das estratégias prescritivas dos adolescentes para lidar com a violência no Brasil, foram encontrados os seguintes temas: política, saúde, educação, emprego, moradia, reflexão, conscientização e diálogo. Assim, em contraste com as crianças, nenhum adolescente mencionou amizade como estratégia para acabar com a violência. Este dado é coerente com essa fase do desenvolvimento, na qual a formação de amizades está menos em evidência do que o exercício intelectual da troca de idéias e da construção de ideais.

\section{Paz versus guerra: em busca de simetria}

As expectativas quanto à assimetria nas idéias de paz e de guerra foram examinadas considerando-se, separadamente, os entrevistados sobre paz e os entrevistados sobre guerra. É possível, ainda, comparar as entrevistas de paz com as de guerra, sem diferençar faixa etária e gênero. Dessa forma, pode-se analisar se a assimetria também se apresenta quando são comparadas amostras diferentes. Se a amostra entrevistada sobre paz fundamentar suas respostas mais em termos da paz negativa do que positiva, e se na amostra sobre guerra predominarem idéias associadas à guerra, detectar-se-á a assimetria observada por Lourenço (1999).

Comparando-se as causas da paz e da guerra, observa-se que a maioria das respostas foi de conteúdo negativo. As causas da paz basearam-se no conceito de paz negativa ou em respostas fundamentadas tanto na paz negativa como na positiva (isto é, respostas mistas). Nas causas da guerra, a maioria das respostas foi orientada para a guerra. Portanto, encontrou-se assimetria entre as causas da paz e causas da guerra.

Analisando-se separadamente as estratégias pró-paz, antiguerra e antiviolência, observa-se que apenas as respostas das crianças apresentaram assimetria. Os adolescentes, por outro lado, sugeriram estratégias de natureza positiva na maioria das respostas. Contudo, comparando-se as porcentagens totais dos três tipos de estratégias, as estratégias prescritivas foram as mais apontadas nos três temas estudados, em razão das grandes porcentagens dos adolescentes. Assim, não foi encontrada a assimetria à qual Lourenço (1999) se referiu, ou seja, de que as duas entrevistas (sobre paz e sobre guerra) mencionariam 
estratégias proscritivas. $\mathrm{O}$ que se observou foi uma assimetria baseada na indicação de respostas prescritivas (de natureza positiva) a todas as estratégias abordadas: pró-paz, antiguerra e antiviolência.

Como descrito na sessão de resultados, a definição de paz no Brasil produziu cinco categorias: ausência de violência, ausência de guerra individual, emoções positivas, atitudes humanitárias e amizade; a definição de guerra no Brasil, três categorias: violência, conflito de interesses e reivindicação. A literatura assinala que as crianças (incluindo as mais velhas, referidas no presente estudo como adolescentes) verbalizam mais sobre guerra do que sobre paz. No presente estudo observou-se o oposto, possivelmente pela especificidade geográfica das questões sobre definição de paz e de guerra (isto é, o Brasil), como também o observamos mediante a categoria reivindicação.

No que tange à qualidade das categorias sobre as definições de paz ou de guerra (se formadas por conteúdos positivos ou negativos), a maior parte delas foi simétrica ao tema abordado. Observou-se que três das cinco categorias da paz são de conteúdo positivo, e duas das três categorias da guerra são de temas negativos. Uma assimetria mais consistente apontaria o inverso na definição da paz, isto é, uma maioria de categorias negativas. Não foi o que se observou.

\section{Considerações finais}

Os participantes mais novos do presente estudo apresentaram dificuldade para conceituar paz no Brasil e guerra no Brasil, dado o considerável número de respostas não-classificáveis. É possível que os conceitos de paz e de guerra não estejam suficientemente inseridos na vida das crianças brasileiras na mesma medida que das européias - estas provenientes de países com histórico mais recente de guerras. Todavia, dada a intensidade com que o brasileiro atualmente vivencia a violência, nos diferentes contextos e classes sociais, as palavras paz e guerra começam a ser inseridas cada vez mais, pelo menos, nos meios de comunicação.

Por outro lado, os adolescentes afirmaram que há guerra no Brasil, quando as pessoas protestam por justiça. Além disso, revelaram que a guerra no Brasil possui duas concepções: uma negativa (a violência) e uma positiva (a luta por direitos). Quanto às estratégias (pró-paz, antiguerra e antiviolência) apresentadas pelos participantes mais velhos, observou-se assimetria nos três tipos abordados, embora baseada na indicação de respostas de natureza positiva, em vez da predominância de respostas negativas, como esperaria Lourenço (1999).
Diferentes áreas de produção de conhecimento têm se envolvido na investigação científica (educação para a paz) e na prática (pacifismo) direcionadas à paz. Para o psicólogo norte-americano David Adams (Tatsch, 2005), assim como para Oppenheimer (1996) e Lourenço (1999), a guerra é uma instituição e, portanto, "os mesmos que inventaram a guerra têm de inventar a paz, porque a paz também é uma instituição" (Tatsch, p. A26). Sobre o caso brasileiro, Adams assinala que há guerra no Brasil, na forma de violência. Esta atual cultura de guerra é, na verdade, a resposta da população para a violência do governo durante a ditadura militar, pois, para Adams, o Estado serve de modelo para seus cidadãos. Segundo o psicólogo norte-americano, "no Brasil, por exemplo, se o governo rouba, o povo rouba também" (Tatsch, p. A26). A solução em direção a uma cultura de paz dependeria do Estado, na opinião de Adams, passando a investir mais em direitos humanos e igualdade do que em militarismo. Além disso, salientou que "a raiva é mais importante para a paz do que para a guerra" (p. A26), pois pode ser transformada em indignação e iniciativa para mudar a cultura da guerra. Foi nesta direção a afirmação dos adolescentes do presente estudo sobre a presença de guerra no Brasil mediante a reivindicação por direitos.

Espera-se que os dados do presente estudo contribuam para o desenvolvimento de programas de educação para a paz. Atentar para a assimetria entre as idéias de paz e de violência envolve desenvolver atividades não apenas interventivas - baseadas na paz negativa - no combate à violência, mas também ações preventivas - concebidas a partir da noção de paz positiva. As estratégias prescritivas, preferidas pelos adolescentes do presente estudo, podem fundamentar o trabalho com estratégias de resolução de conflito, por exemplo, na escola.

\section{Referências}

Aron, R. (1986). Paz e guerra entre as nações. Brasilia, DF: UnB.

Bardin, L. (1977). Análise de conteúdo (L. A. Reto \& A. Pinheiro, Trads.). Lisboa: Edições 70.

Biaggio, A. M. B. \& Souza, L. K. (2001). Atitudes em relação à paz, à guerra e à violência em cinco cidades brasileiras. Revista do Departamento de Psicologia da UFF, 13(2), 65-82.

Guimarães, M. R. (2003). Educação para a paz na crise da metafísica: sentidos, tensões, dilemas (Tese de Doutorado). Porto Alegre, RS: Universidade Federal do Rio Grande do Sul. 
Hägglund, S. (1999). Peer relationships and children's understanding of peace and war: A sociocultural perspective. Em A. Raviv, L. Oppenheimer \& D. Bar-Tal (Orgs.). How children understand war and peace: A call for international peace education (pp. 190-207). San Francisco: Jossey-Bass.

Hakvoort, I. M. T. (1996). Conceptualization of peace and war from childhood through adolescence: $A$ social-cognitive developmental approach (Tese de Doutorado). Amsterdã: Universidade de Amsterdã - Faculdade de Psicologia.

Hakvoort, I. M. T. \& Oppenheimer, L. (1998). Understanding peace and war: A review of developmental psychology research. Developmental Review, 18, 353-389.

Lourenço, O. M. (1999). Toward a positive conception of peace. Em A. Raviv, L. Oppenheimer \& D. BarTal (Orgs.). How children understand war and peace: $A$ call for international peace education (pp. 91-108). San Francisco: Jossey-Bass.

McLernon, F. \& Cairns, E. (1999). Children, peace, and war in Northern Ireland. Em A. Raviv, L. Oppenheimer \& D. Bar-Tal (Orgs.). How children understand war and peace: A call for international peace education (pp. 145-160). San Francisco: Jossey-Bass.

Oppenheimer, L. (1996). War as an institution, but what about peace? Developmental perspectives. International Journal of Behavioral Development, 19(1), 201-218.

Oppenheimer, L., Bar-Tal, D. \& Raviv, A. (1999). Introduction. Understanding peace, conflict, and war.
Em A. Raviv, L. Oppenheimer \& D. Bar-Tal (Orgs.). How children understand war and peace: $A$ call for international peace education (pp. 1-24). San Francisco: Jossey-Bass.

Punamäki, R. L. (1999). Concept formation of war and peace: A meeting point between child development and a politically violent society. Em A. Raviv, L. Oppenheimer \& D. Bar-Tal (Orgs.). How children understand war and peace: A call for international peace education (pp. 127-144). San Francisco: Jossey-Bass.

Raviv, A., Bar-Tal, D., Koren-Silvershatz, L. \& Raviv, A. (1999). Beliefs about war, conflict, and peace in Israel as a function of developmental, cultural, and situacional factors. Em A. Raviv, L. Oppenheimer \& D. Bar-Tal (Orgs.). How children understand war and peace: A call for international peace education (pp. 161189). San Francisco: Jossey-Bass.

Tatsch, C. (2005). "Na guerra não há lugar para ódio", diz especialista. Folha de São Paulo, 23/01, p. A26.

Tavares dos Santos, J. V. \& Russo, M. (2003). Espacialização das violências em Porto Alegre: cidade complexa e diferenciada. Porto Alegre, RS: Secretaria de Direitos Humanos e Segurança Urbana.

Recebido em fevereiro de 2005 Reformulado em setembro de 2006 Aprovado em setembro de 2006

Sobre as autoras:

Luciana Karine de Souza é professora adjunta no Departamento de Psicologia da Faculdade de Filosofia e Ciências Humanas da Universidade Federal de Minas Gerais. É psicóloga pela Universidade Federal do Rio Grande do Sul, com mestrado e doutorado pelo PPG em Psicologia do Desenvolvimento da UFRGS. Seus interesses de pesquisa estão na psicologia do desenvolvimento e nos relacionamentos pessoais e sociais.

Tania Mara Sperb é professora colaboradora da Universidade Federal do Rio Grande do Sul, membro do PPG em Psicologia do Desenvolvimento. Psicóloga, obteve o Msc. e o Ph.D em Psicologia do Desenvolvimento pela University of London. Coordena o Centro de Estudos da Linguagem e da Interação Social, pesquisando na área de desenvolvimento da linguagem e da cognição, com ênfase em narrativa e interação criança-criança. 
